\title{
DINAMIKA COLLABORATIVE GOVERNANCE DALAM FESTIVAL LEGU GAM SEBAGAI WISATA KULTURAL KOTA TERNATE
}

\author{
Sumitro S. Syawal ${ }^{1}$ dan Suleman Samuda ${ }^{2}$
}

\begin{abstract}
This research aims to know the dynamics of collaborative governance process in implementing Legu Gam as cultural tourism of Ternate City, which the process of collaboration involves multi-stakeholder in accordance with capacity, motivation and extent of involvement starting from planning process and implementation from each stakeholder. Based on the focus, this research used qualitative descriptive approach with data analysis method refers to the interactive analysis model. The results showed that collaboration forum was formed based on Idin Kolano or The decree of the Sultanate Ternate. The value that underlies the Sultanate Ternate in organizing Legu Gam was to preserve adat seatorangin in daylife lifeamid waning of indigenous values and culture of Ternate. Meanwhile by holding Festival of Legu Gam, Ternate municipality government aimed to develop society economy of Ternate city.
\end{abstract}

Keywords: Collaborative Governance, Cultural Tourism, Legu Gam, Ternate City

\begin{abstract}
ABSTRAK
Penelitian ini ditujukan untuk mengetahui dinamika proses collaborative governance dalam pelaksanaan Legu Gam sebagai wisata kultural Kota Ternate, dimana proses kolaborasi melibatkan multi-stakeholder sesuai dengan kapasitas, motivasi dan sejauhmana keterlibatan mulai dari proses perencanaan dan implementasi dari masingmasing stakeholders. Sesuai dengan fokusnya, penelitian ini menggunakan pendekatan deskriptif kualitatif dengan metode analisis data mengacu pada model analisis interaktif. Hasil penelitian menunjukkan bahwa forum kolaborasi dibentuk berdasarkan Idin Kolano atau surat keputusanKesultanan Ternate.Nilai yang melandasi Kesultanan Ternate dalam menyelenggarakan legu gam adalah membudayakan adat seatorang dalam kehidupan sehari-hari ditengah memudarnya nilai-nilai adat dan budaya Ternate, sementara itu melalui Festival legu Gam, Pemerintah Kota Ternate mengembangan ekonomi kerakyatan masyarakat Kota Ternate.
\end{abstract}

Kata Kunci: Collaborative Governance, Wisata Kultural, Legu Gam, Kota Ternate

1,2 Dosen, Ilmu Administrasi Negara, FISIPOL, Universitas Muhammadiyah Maluku Utara. Email: sumitro.ssyawal@ummu.ac.id 


\section{PENDAHULUAN}

Studi ini akan menganalisis bagaimana dinamika collaborative governance yang terjadi dalam pelaksanaan Festival Legu Gam sebagai pariwisata kultural di Kota Ternate yang bertaraf nasional. Visi dari pelaksanaan festival Legu Gam itu sendiri adalah untuk memperkenalkan khasanah kebudayaan Moloku Kie Raha kepada masyarakat luas. Tentunya, dalam manifestasi ide besar ini dibutuhkan kolaborasi antar stakeholders baik Kesultanan Ternate dengan pemerintah daerah dan pemerintah pusat atau Kesultanan Ternate dengan pihak swasta, masyarakat, pelaku pariwisata. Dalam melakukan kerjasama yang melibatkan multi-stakehoder dibutuhkan wadah atau institusi yang akan mengelola kerjasama tersebut. Pada titik ini collaborative governance dipandang sebagai sebuah strategi penting untuk mengelola kerjasama yang melibatkan berbagai stakeholder. Collaborative governance merupakan sebuah paradigma baru dalam memahami eksistensi interaksi multi-stakeholder, tidak lagi hanya sebatas memahami kesepahaman yang terbangun dalam interaksi yang berujung pada kesepakatan tetapi penting untuk dipahami lebih mendalam (Nasrulhaq, 2014).
Festival Legu Gam merupakan potensi pariwisata yang bisa dikembangkan menjadi wisata unggulan Kota Ternate mengingat semenjak tahun 2013 Festival Legu Gam sendiri telah masuk menjadi kalender destinasi wisata nasional oleh Kementerian Pariwisata dan Ekonomi Kreatif RI. Secara historis Legu Gam merupakan khasanah kebudayaan kesultanan Ternate yang dilakukan sebagai tradisi adat istiadat yang melibatkan para bangsa, Soangare, Ngofa se Dano-dano dan balakusu sekano kano kesultanan Ternate sebagai pranata sosial masyarakat adat. Legu Gam juga bisa dimaknai sebagai bentuk apresiasi kesultanan terhadap rakyatnya. Puncak perayaan Legu Gam ditetapkan sesuai dengan hari kelahiran Sultan Mudaffar Sjah yang juga merupakan Sultan ke-48 dari Kesultanan Ternate. Beberapa kegiatan kebudayaan (ritual budaya) yang sering dilakukan saat pelaksanaan Legu Gam, yaitu: (1) Ritual Kololi Kie Mote Ngolo, yakni mengelilingi Pulau Ternate melalui laut menggunakan kora-kora (perahu tradisional); (2) Ritual Fere Kie, yakni mendaki di Puncak Gunung Gamalama yang melibatkan masyarakat adat. Ritual yang ditandai dengan pembacaan doa pada makam keramat di 
puncak Gunung Gamalama tersebut bertujuan memohon perlindungan kepada Tuhan Yang Maha Kuasa agar masyarakat Ternate dan daerah lainnya di Maluku Utara terbebas dari bencana; dan (3) Ritual Gam Ma Cahaya, yakni pawai obor mengelilingi Pulau Ternate. Ritual yang melibatkan ribuan masyarakat adat Kesultanan Ternate ini bertujuan meminta perlindungan kepada Tuhan Yang Maha Esa agar Ternate terhindar dari segala mala petaka.

Pada tahun 2006 pelaksaaan Legu Gam mulai melibatkan pemerintah daerah diantaranya pemerintah Kota Ternate dan Pemerintah Propinsi. Pelibatan pemerintah daerah dalam hajatan Legu Gam bukan tanpa alasan, keterbatasan anggaran yang mendasari pihak kesultanan untuk mengajak para pemangku kepentingan di bidang pariwisata untuk berkolaborasi dalam mengemas tradisi leluhur menjadi sebuah daya tarik wisata yang bertaraf nasional. Nilai yang melandasi pihak kesultanan Ternate untuk melaksanakan festival Legu Gam yakni untuk melestarikan nilai-nilai adat seatorang ditengah gencarnya infiltrasi budaya asing, sebaliknya nilai yang melandasi pemerintah kota Ternate adalah melalui festival Legu Gam Pemerintah Ternate meningkatkan ekonomi kerakyatan.
Kerjasama dalam pelaksanaan festival Legu Gam yang melibatkan berbagai stakeholders baik itu masyarakat, pihak swasta dan pemerintah dengan kapasitas yang dimiliki masing-masing stakeholders dengan beragam kepentingan yang terikat untuk mencapai tujuan bersama akan membentuk multipartner governance yang bersinergi secara peran dan program yang bersifat hybrid (Lemos dan Agrawal, 2006) dikenal dengan term collaborative governance (D. Ngar-yin dan P. Hills. 2010: 89). Emerson et.al (2011) menyatakan collaborative governance sebagai struktur proses dalam pengambilan keputusan dan manajemen kebijakan yang melibatkan aktornegara dan non negara secara konstruktif di seluruh wilayah batas-batas badan publik, tingkat pemerintahan, dan/atau publik, serta swasta dalam lingkup untuk melaksanakan tujuan umum yang tidak dapat diselesaikan oleh lembaga negara. Menurut Robertson \& Choi (dalam Kumorotomo, Wahyudi. Dkk 2013:10) collaborative governance merupakan sebuah proses kolektif dan egalitarian bagi setiap stakeholders yang terlibat, dengan otoritas substantif yang dimiliki dalam pengambilan keputusan serta memiliki kesempatan yang sama untuk merefleksikan aspirasi (kepentingan) 


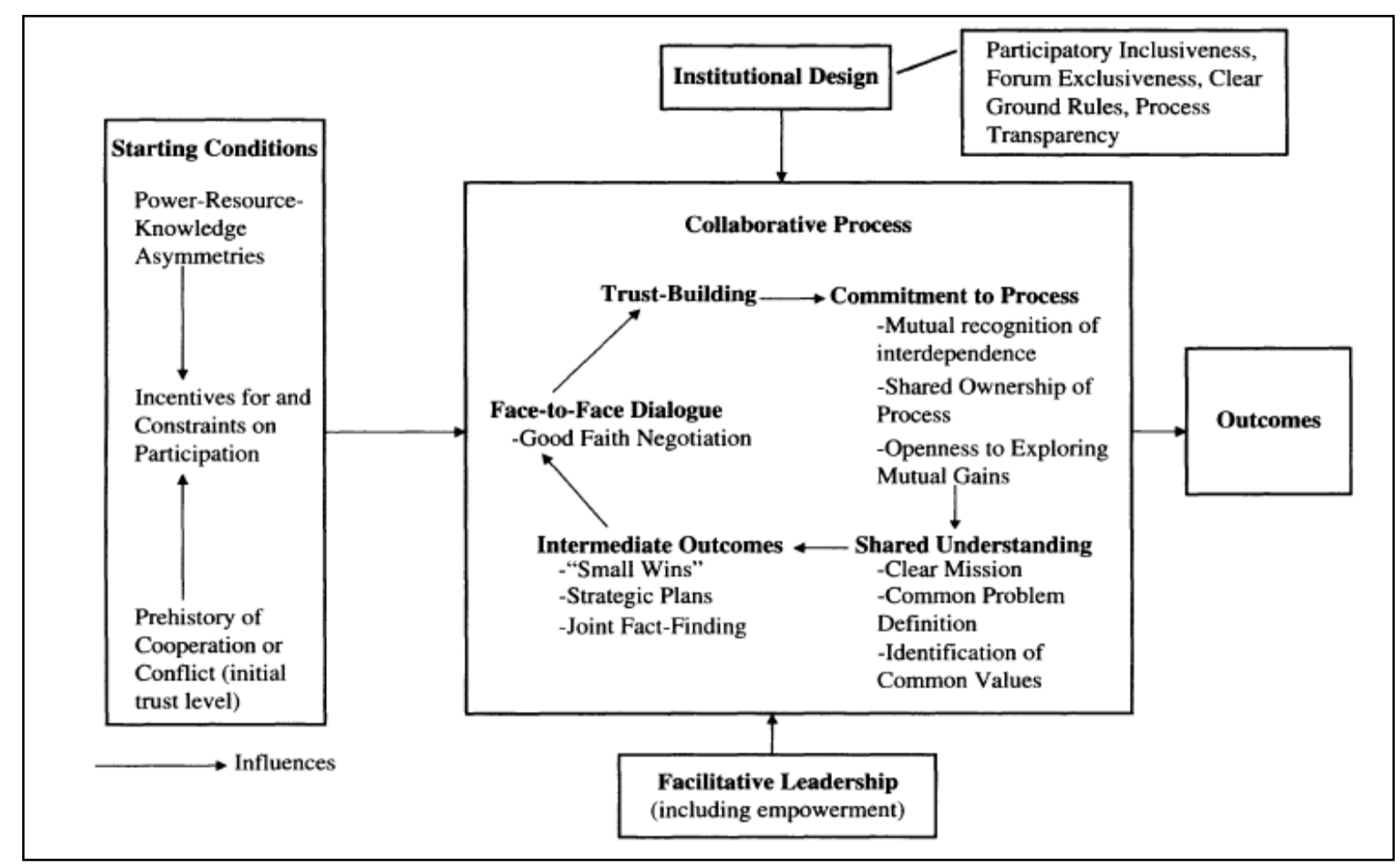

(Sumber: Ansell and Gass. 2007:550)

\section{Gambar 1: A Model of Collaborative Governance}

dalam proses tersebut. Hampir sejalan dengan defenisi yang disampaikan oleh Robertson \& Choi, Fosler (dalam Dwiyanto, Agus. 2010:261) menjelaskan secara terperinci mengenai kerjasama yang bersifat kolaboratif yang melibatkan berabagai pihak yang dilakukan secara intensif dengan upaya secara sadar untuk melakukan alignment dalam tujuan, agenda, strategi dan sumber daya serta aktifitas.

\section{Secara umum collaborative} governance diartikan sebagai suatu bentuk susunan kepemerintahan, dimana satu atau lebih instansi pemerintah secara langsung berhubungan dengan stakeholder nonnegara dalam sebuah proses pengambilan keputusan yang formal berbasis konsensus, deliberatif dan menuju pada formulasi atau impelementasi kebijakan public atau dapat pula dalam program atau asset publik (Ansell and Gass. 2007).

Model collaborative governance yang digambar oleh Anshel and Gash memiliki 4 variabel yang dimulai dari kondisi, desain kelembagaan, kepemimpinan, dan proses kolaboratif. Masing-masing variabel ini dapat dipilah menjadi variabel yang lebih baik. Dimana variabel proses kolaboratif diperlakukan sebagai inti dari model ini, dengan kondisi awal, desain institusional, dan variabel kepemimpinan yang diwakili sebagai kontribusi kritis atau konteks untuk proses 
kolaboratif. Kondisi awal menetapkan tingkat kepercayaan, konflik, dan modal sosial yang menjadi sumber daya atau kewajiban selama berkolaborasi. Desain kelembagaan menetapkan aturan dasar di mana kolaborasi berlangsung. Kemudian kepemimpinan memberikan mediasi dan fasilitasi penting untuk proses kolaboratif. Proses kolaboratif itu sendiri sangat bersifat iteratif dan nonlinier.

Collaborative governance dalam pelaksanaan pariwisata dimaksudkan untuk membangun pariwisata berkelanjutan membutuhkan semua stakeholders baik pemerintah, civil society, pelaku wisata dan masyarakat lokal dalam rangka membangun kesepahaman dan komitmen serta rasa tanggungjawab (sense of responsibility) dalam pengelolaan pariwisata. Untuk menambah pemahaman penulis dalam memahami dinamika collaborative governance yang terjadi dalam festival Legu Gam, penulis mengacu pada kerangka dynamic collaborative governance yang diusulkan oleh Emerson et.al (2011), dimana dinamika pola kolaborasi dipandang sebagai suatu siklus atau interaksi yang terjadi secara berulang dan terdiri atas tiga komponen utama yang interaktif, yakni: keterlibatan, motivasi bersama dan kapasitas untuk melakukan aksi bersama. Ketiga komponen tersebut bekerja secara bersama-sama dengan cara interaktif antara sesama komponen secara berulang-ulang untuk menghasilkan aksiaksi kolaboratif dalam rangka mengimplementasi tujuan bersama yang berdampak secara eksternal maupun internal dari sistem kolaboratif tersebut.

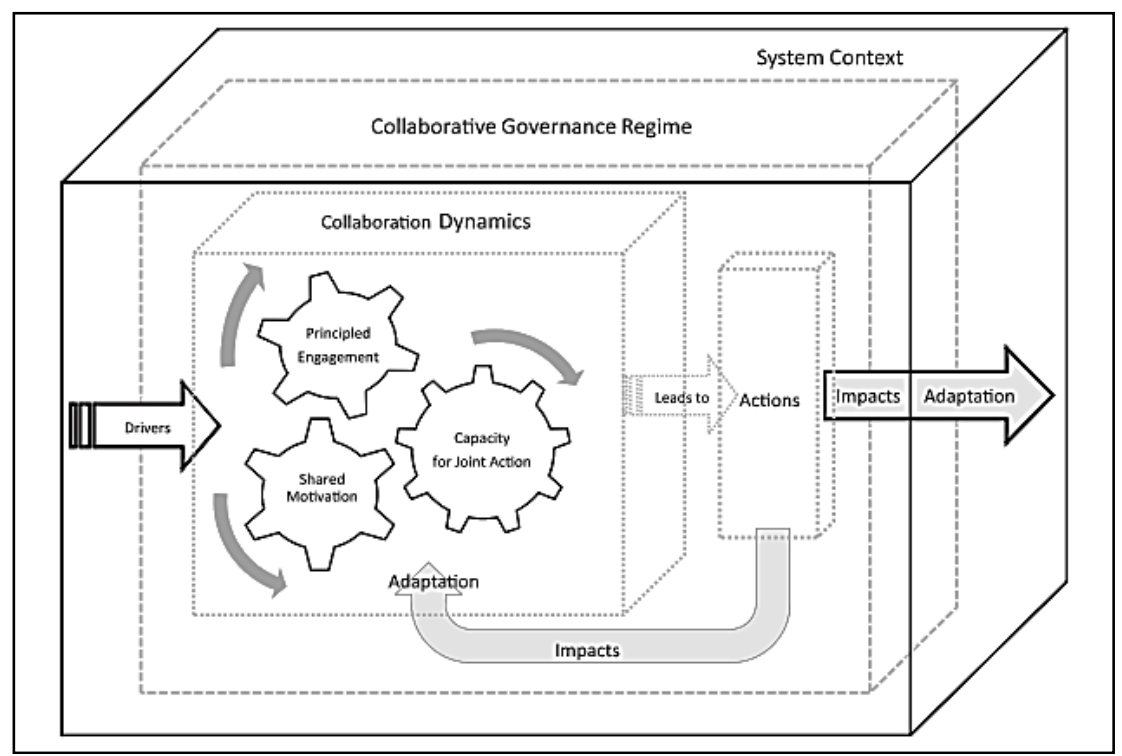

(Sumber: Emerson, Nabatchi and Balogh. 2011:6)

Gambar 2. The Integrative Framework for Collaborative Governance 
Pada praktiknya collaborative governance tidaklah berjalan tanpa menemui kendala yang nantinya menghambat proses kolaboratif. Menurut Hardy dan Philip (1998), Greewnald. (2008) menyatakan ada beberapa faktor yang menentukan keberhasilan atau kegagalan dalam collaborative governance terdiri dari: (1) Otoritas adalah hak yang diakui keadaan suatu orang atau institusi untuk memberikan penilaian, membuat keputusan, atau melakukan aksi tertentu; (2) Kekuasaan yang berbasis sumberdaya dapat berarti ketergantungan diantara organisasiorganisasi yang terkait dalam kolaborasi dan kemampuan mereka untuk mengeluarkan sumberdaya tersebut; (3) Legitimasi diskursif merujuk pada kemampuan suatu organisasi untuk merepresentasikan sebuah diskursif atau berbicara atas nama wacana diarena publik.

\section{METODE}

Penelitian ini merupakan penelitian kualitatif yang berusaha memahami dan menafsirkan makna suatu peristiwa interaksi tingkah laku manusia dalam situasi tertentu menurut perspektif peneliti sendiri. Penelitian kualitatif deskriptif, dimaksudkan untuk mengeksplorasi dan klarifikasi mengenai suatu fenomena atau kenyataan sosial. Untuk itu, penelitian ini berusaha untuk mengambarkan secara apa adanya (emik) jalinan hubungan yang terjadi dan fakta yang tampak dilapangan dalam pelaksanaan collaborative governance yang berlangsung diantara instansi pemerintah dan instansi non pemerintah serta pihak kesultanan Ternate dalam pelaksanaan Legu Gam sebagai agenda pariwisata Kota Ternate berbasis wisata kultural. Lokasi penelitian bertempat di Kota Ternate dipilih sebagai objek penelitian ini dilaksanakan dikarenakan letak pelaksanaan event tahunan Legu Gam bertempat di Kota Ternate.

Unit analisis dalam sebuah penelitian merupakan sebuah elemen penting dan keberadaannya sangat krusial dalam membangun kerangka konseptual, teknik pengumpulan data dan penentuan sampel penelitian secara empirik. Unit analisis dalam penelitian bisa lebih dari satu unit analisis. Dengan mengidentifikasi unit analisis akan membantu peneliti mengorganisir data dan memudahkan analisis pada tahapan selanjutnya. Unit analisis dalam penelitian ini adalah festival Legu Gam.

Penelitian ini menggunakan dua jenis data yakni data primer dan data sekunder. Data primer merupakan data 
yang dikumpulkan langsung dari lapangan melalui wawancara dengan informan. Informan dalam penelitian ini meliputi: Dinas Kebudayaan dan Pariwisata Kota Ternate, Kesultanan Ternate, informan dari Panitia Pelaksanaan Legu Gam dan pihak swasta. Data sekunder yang digunakan dalam penelitian ini dikumpulkan dari sumber lain sebagai pendukung data primer yang didapat melalui buku atau referensi atau dokumen-dokumen yang terkait dengan penelitian ini. data sekunder meliputi Rencana Induk Pariwisata Kota Ternate, Agenda Pariwisata Kota Ternate dan data tentang pelaksanaan Legu Gam.

\section{HASIL DAN PEMBAHASAN}

\section{Legu Gam: Kontestasi Transformasi}

\section{Kebudayaan}

Berawal dari pemikiran permaisuri

Boki Nita Budhi Susanti untuk melaksanakan sebuah kegiatan budaya sebagai upaya untuk menghidupkan kembali tradisi yang dibingkai dalam bentuk pesta rakyat atau pesta kebudayaan yang dilaksanakan masyarakat adat guna memperingati hari kelahiran Sultan Ternate Mudaffar Syah pada bulan april. Namun, Legu Gam sendiri memiliki tradisi panjang yang telah ada sejak masa lampau, Legu Gam hadir dalam bentuk tarian sakral, yakni Tari Legu (awalnya hanya dipentaskan di dalam keraton) yang bermakna pesta rakyat yang dilakukan dengan tari-tarian.

Semenjak dilaksanakan pertama kali pada tahun 2002, Legu Gam sebagai representasi kearifan lokal dalam bentuk seni dan budaya, sejak tahun 2006 tari ini telah bertranformasi menjadi sebuah kegiatan budaya yang bertaraf nasional. Dari sebuah kegiatan seni dan budaya yang digelar pada lingkungan keraton dalam bentuk pembacaan doa selamat yang dipimpin oleh bobato dunia dan bobato Akhirat, bergeser menjadi sebuah festival yang tidak hanya terdiri dari adat dan budaya kesultanan Ternate tetapi meliputi adat dan budaya Moloku Kie Raha. Makna dari budaya ini dalam Bahasa Ternate adalah 4 kerajaan dalam satu kesatuan yaitu: 1) Kerajaan Ternate. 2) Kerajaan Tidore; 3) Kerajaan Jailolo dan 4) Kerajaan Bacan, serta mengakomodir budaya nasional dan budaya populer saat ini dalam beberapa kegiatan (di luar ritual wajib).

Bila awalnya hanya dalam bentuk tarian Legu, kini legu gam bertransformasi menjadi sebuah festival yang kaya akan nilai-nilai luhur adat dan budaya Moloku Kieraha. Legu Gam tidak lagi hanya merepresentasikan seni dan budaya 
Moloku Kieraha dalam bingkai adat seatorang namun kini Legu Gam menjadi instrumentasi untuk untuk memperkenalkan identitas budaya lokal dan keragaman budaya Indonosia. Perubahan tersebut dilakukan sebagai upaya untuk mengakomodasi pelibatan masyarakat luas terhadap kegiatan Legu Gam itu sendiri, bahkan pada beberapa tahun belakangan ini Festival Legu Gam lebih membuka ruang kemajemukan bagi etnis yang hidup di Ternate. Keberagaman etnik dan budaya terdiri atas entik asli Maluku Utara yang dikelompokkan ke dalam kelompok Gam Madihutu (penduduk asli) dan etnik Dai' Isa (pendatang).

Ada tiga rangkaian dalam tradisi Legu Gam, pertama, Doru Gam atau kujungan kunjungan Sultan ke daerahdaerah dalam wilayah kesultanan Ternate; kedua, Kololi Kie. Yang bermakna mengelilingi gunung atau dalam bahasa keseharian masyarakat Ternate disebut kegiatan tawaf gunung yang dimaksudkan untuk memohon perlindungan atau keselamatan kepada yang maha kuasa. Dan ketiga, Fere Kie atau mendaki puncak gunung.

Dalam dinamika pelaksanaan festival Legu Gam tidak lagi merupakan representasi seni dan budaya etnis Ternate tetapi mulai meluas menjadi kontestasi seni dan budaya Moloku Kie Raha. Tepatnya pada tahun 2008, pelaksanaan festival Legu Gam mulai merepresentasikan nuansa kebudayaan moloku kieraha dan dipadu padankan dengan budaya kontemporer. Namun pada pelaksanaannya Legu Gam tetap mengacu pada falsafah adat seatorang untuk memaknai keragaman budaya dan etnik untuk pembangunan Maluku Utara.

\section{Dinamika Pola Collaborative Governance dalam Pelaksanaan}

\section{Festival Legu Gam}

Dalam pelaksanaan festival Legu Gam, kegiatan dibagi dalam dua bentuk kegiatan yakni: pertama, ritual wajib berupa pembacaan doa selamat dan beberapa bentuk ritual adat lainnya seperti tarian legu, kololi kie dan fere kie. Kedua, kegiatan kepariwisataan. Dalam kegiatan ini ditampilkan beberapa bentuk kebudayaan Moloku Kie Raha dimasudkan sebagai bentuk pelestraian kebudayaan adat setempat serta bentuk kegiataan hiburan rakyat lainnya serta kegiatan yang bernilai edukasi bagi masyarakat.

Kolaborasi bisa dimaknai sebagai bentuk lain dari aspirasi atau tujuan-tujuan bagi pemerintah dalam berinteraksi 
dengan mitra-mitra, yang bisa saja kolaborasi bukan dalam sebuah institusi formal belaka tetapi kolaborasi merupakan a way of behaving atau cara berperilaku maupun bersikap institusi pemerintah dengan melibatkan manajemen publik dalam suatu program atau kegiatan (Lemos dan Agrawal. 2006).

Dinamika aksi kolaborasi dapat dikatakan efektif dan efisien bila dalam kolaborasi didalamnya memuat beberapa aspek yang harus dipenuhi oleh setiap stakeholder yang terlibat yakni: keterlibatan, motivasi bersama, kapasitas untuk melakukan kolaborasi (Emerson et.al 2011).

Dinamika koloborasi dalam pelaksanaan Legu Gam dilihat dengan bagaimana keterlibatan setiap stakeholders dalam pengambilan keputusan dan partisipasi dalam setiap kegiatan. Bagaimana motivasi bersama dapat terbentuk dalam pembagian peran setiap stakeholder, legitimasi internal serta komitmen dari setiap stakholder dalam wadah kolaborasi. Dinamika kolaborasi dapat terjadi dengan adanya kapasitas untuk melakukan aksi bersama. Untuk melihat proses kolaborasi dalam festival Legu Gam akan di uraikan pada Tabel 1.

Untuk melihat proses kolaborasi dalam pelaksanaan festival Legu Gam, penting untuk kita melihat dinamika yang terjadi dengan mengacu pada kerangka dynamic collaborative governance yang diusulkan oleh Emerson et.al (2011), dimana dinamika pola kolaborasi dipandang sebagai suatu siklus atau interaksi yang terjadi secara berulang dan terdiri atas tiga komponen utama yang interaktif yakni: keterlibatan, motivasi bersama dan kapasitas untuk melakukan aksi bersama.

\section{Keterlibatan Stakeholder}

Patut diapresiasi melalui Idin Kolano kesultanan Ternate dapat merangkul pemangku kepentingan untuk berkolaborasi dalam mensukseskan festival Legu Gam. Kesultanan Ternate tidak lagi menjadi aktor tunggal dalam melestarikan adat dan budaya Ternate tetapi melibatkan semua kalangan yang terdiri dari aktor lintas organisasi lainnya meliputi aktor negara (pemerintah daerah) dan aktor non negara (swasta, akademisi dan masyarakat). Perbincangan keterlibatan stakeholders dalam collaborative governancedi festival Legu Gam terkadang masih diperbincangkan, antara substansi atau simbol. Adapun praktek kolaborasi yang tercermin dengan dibentuknya wadah kolaborasi dalam bentuk panitia pelaksana serta adanya 
Tabel.1 Matrix Dinamika Pola Kolaborasi dalam Festival Legu Gam

\begin{tabular}{|c|c|c|}
\hline No & $\begin{array}{c}\text { Aspek Dinamika Pola } \\
\text { Kolaborasi }\end{array}$ & $\begin{array}{l}\text { 1. Kesultanan Ternate } \\
\text { 2. Pemerintah Kota Ternate } \\
\text { 3. Pemerintah Propinsi Maluku Utara } \\
\text { 4. Pihak Sponsor }\end{array}$ \\
\hline \multirow[t]{2}{*}{1} & Keterlibatan & Uraian \\
\hline & $\begin{array}{ll}\text { Partisipasi dalam } \\
\text { Pengambilan } \\
\text { Keputusan }\end{array}$ & $\begin{array}{l}\text { Adanya forum kolaborasi menunjukkan bahwa keterwakilan } \\
\text { dalam proses kolaborasi tidak sebatas simbolis melainkan } \\
\text { penegasan secara subtansi keterwakilan pada proses } \\
\text { kolaborasi. Dimana forum kolaborasi berperan sebagai } \\
\text { instrumen untuk merumuskan bentuk, jenis kegiatan dan } \\
\text { strategi pencapaian serta pengambilan keputusan. } \\
\text { Pengambilan keputusan dalam kelembagaan kolaborasi } \\
\text { diputuskan dalam setiap forum kolaborasi dan disetujui } \\
\text { setiap aktor, namun keputusan yang diambil hanya sebatas } \\
\text { pada bentuk kegiatan kepariwiataaan sedangkan ritual adat } \\
\text { tetap dilaksanakan oleh perangkat adat kesultanan Ternate. }\end{array}$ \\
\hline \multirow[t]{2}{*}{2} & Motivasi Bersama & Uraian \\
\hline & Pembagian peran & $\begin{array}{l}\text { Terdapat dua bentuk kegiatan dalam festival Legu Gam } \\
\text { yakni: ritual wajib adat dan kegiatan kepariwisataan. } \\
\text { Kegiataan ritual wajib adat ditangani oleh perangkat adat } \\
\text { kesultanan Ternate sedangkan kegiatan kepariwisataan di } \\
\text { tangani oleh panitia festival Legu Gam. } \\
\text { Ketua Panitia merupakan representasi kultural yang } \\
\text { mewakili ngofa sedano (anak cucu/keturunan) sultan dan } \\
\text { juga memiliki pengalaman karena menjadi ketua panitia } \\
\text { sejak 2006-2014. Namun pada pelaksanaan fetival Legu } \\
\text { Gam periode } 2015 \text { dan } 2016 \text { ketua panitia di jabat oleh } \\
\text { wakil walikota dan masih anak keturunan sultan Ternate } \\
\text { namun tidak memiliki pengalaman sehingga pelaksaan } \\
\text { festival Legu Gam mengalami kemunduran dengan tidak } \\
\text { lagi menjadi destinasi wisata nasional. }\end{array}$ \\
\hline \multirow[t]{2}{*}{3} & Kapasitas & Uraian \\
\hline & $\begin{array}{l}\text { Kepemimpinan } \\
\text { Kolaborasi }\end{array}$ & $\begin{array}{l}\text { Kelembagaan kolaborasi sudah dibentuk melalui idin } \\
\text { kolano, sebagai wadah kolaborasi merepresentasikan } \\
\text { stakeholder yang terlibat. Pengambilan keputusan dilakukan } \\
\text { dalam wadah kolaborasi tetapi dalam ritual wajib adat } \\
\text { pengambilan keputusan dibawah kendali pihak kesultanan, } \\
\text { panitia festival Legu Gam hanya bertindak sebagai } \\
\text { fasilitator. } \\
\text { Peran pemimpin dalam festivalLegu Gam adalah } \\
\text { menginisiasi forum kolaborasi guna menggalang dukungan } \\
\text { dan sinergi program dengan pemda serta pihak Swasta } \\
\text { untuk pendanaan }\end{array}$ \\
\hline
\end{tabular}

Sumber: Data Primer 
forum kolaborasi telah mengindikasikan adanya pengutamaan muatan substansi.

Dalam beberapa hal, adanya forum kolaborasi menunjukkan bahwa keterlibatan stakeholders dalam proses kolaborasi bukan semata-mata hanya sebagai simbol melainkan sebuah penegasan subtansi atas keterlibatan stakeholders dalam merumuskan kembali hakikat pembentukan dan pengembangan prinsip-prinsip bersama yang sering diungkap dalam berbagai perspektif aktoruntuk merumuskan kembali tujuan bersama.

Forum Kolaborasi merupakan salah satu bentuk deliberasi dalam pengambilan keputusan dimana forum tersebut dirancang untuk memastikan bahwa setiap rencana kegiatan yang telah disusun yang melibatkan multi stakeholder dapat berjalan baik dan sinergi setiap peran bisa terlaksana. Dalam pelaksanaan festival Legu Gam, forum kolaborasi terdiri atas forum yang bersifat rutin dan forum kolaborasi yang bersifat insidentil (sesuai dengan kebutuhan). Forum kolaborasi yang bersifat rutin adalah rapat panitia yang dilaksanakan semenjak panitia festival Legu Gam di bentuk melalui Idin Kolano (surat keputusan Sultan Ternate) pada bulan oktober. Rapat panitia dilaksanakan untuk merumuskan bentuk kegiatan, susunan kegiatan, jenis kegiatan dan strategi untuk melaksanakan tahapan kegiatan yang telah di bentuk. Berikut akan diuraikan forum kolaborasi pada Tabel 2.

\section{Motivasi Bersama}

$$
\text { Emerson et.al }
$$

mendefenisikan motivasi bersama adalah as a self-reinforcing cycle consisting of four elements: mutual trust, understanding, internal legitimacy, and commitment. Dalam arti yang lain motivasi bersama meliputi pembagian peran, legitimasi internal dan komitmen. Setiap stakeholder yang terlibat merupakan representasi kelembagaan yang diwakili dan tentunya tidak terlepas dari individu para stakeholders tersebut. Bagaimanapun juga representasi kelembagaan yang dimainkan

Tabel 2. Forum Collaborative Governance dalam Festival Legu Gam

\begin{tabular}{|c|c|c|c|}
\hline No & Nama Forum & Peserta & Sifat \\
\hline 1 & Rapat Panitia & Seluruh Panitia & Rutin \\
\hline 2 & Bisnis Meeting & Panitia dengan Sponsorship & Insidentil \\
\hline 3 & Rapat Kordinasi & $\begin{array}{c}\text { Panitia dengan Pemerintah atau } \\
\text { Pihak Kesultanan }\end{array}$ & Insidentil \\
\hline
\end{tabular}

Sumber: Data primer 
mengandung nilai dan motivasi lembaga yang diwakili tersebut tidak bisa dipisahkan dari nilai dan motivasi yang dimiliki individu.

\section{Pembagian Peran}

Ketidakseimb-angan pembagian dalam kolaborasi yang ditimbulkan karena perbedaan kapasitas, organisasi, sumber daya untuk berpartisipasi merupakan gejala umum yang terjadi dalam collaborative governance. Fenomena seperti ini dalam pengelolaan kolaboratif akan rentan terhadap manipulasi oleh aktor yang kuat, fakta yang dijumpai di lapangan memperlihatkan bahwa fenomena ketidakseimbangan pembangian peran juga dijumpai dalam pelaksanaan festival Legu Gam, dimana struktur kepanitiaan yang menjadi wadah kolaboratif diisi oleh berbagai stakeholders yang mewakili status, organisasi, kewenangan, representasi kewilayahan dan sumberdaya. Dari kelima stakeholders tersebut, aktor yang terlibat dalam panitia pelaksana festival Legu Gam yang merepresentasikan wilayah selatan Kota Ternate, tidak mendapat peran penting dalam wadah kolaborasi tersebut. Hal yang terjadi berbeda dengan aktor yang mewakili status sebagai ngofa se dano dan balakusu se kano-kano, atau pemerintah Kota Ternate dan korporasi.

Pembagian peran dalam festival Legu Gam dibagi berdasarkan bentuk kegiatan yakni: pertama, untuk ritual wajib yang bernuansa adat, stakeholders dari pihak kesultanan memegang peran utama dalam kegiatan tersebut baik dalam pengambilan keputusan bentuk kegiatan seperti apa, bagaimana proses pelaksanaan kegiatan. Fakta seperti ini menunjukkan bahwa perangkat adat pada saat bersamaan selain menjadi bagian dalam panitia juga berperan sebagai aktor adat yang memiliki kewenangan, dimana kewenangan tersebut dalam implementasinya tidak dapat di pengaruhi oleh panitia festival Legu Gamitu sendiri. Artinya bahwa panitia hanya berperan sebagai fasilitator dalam pelaksnaan ritual adat itu sendiri. Kedua, kegiataan kepariwisataan, dikelola langsung oleh panitia festival Legu Gam. Dalam kegiatan kepariwisataan ini, setiap stakeholders dilibatkan sesuai dengan kapasitas yang dimiliki.

Legitimasi Internal. Legitimasi internal dalam proses kolaborasi merupakan pengakuan yang bersumber dari internal kolaborasi itu sendiri. 
Legitimasi internal dalam proses kolaborasi dapat diperoleh bila aktoraktor dalam kolaborasi kredibel dan berintgritas serta berpengalaman dalam mengelola kegiatan. Legitimasi internal dalam collaborative governance pelaksanaan festival Legu Gam adalah (1) Peran Ketua Panitia yang merepresentasikan kapasitas kultural dan Struktural; (2) Ketua Panitia pada periode 2006-2014 memiliki pengalaman dalam mengelola proses kolaborasi sehingga hasil kolaborasi menempatkan festival sebagai destinasi wisata nasional oleh Kementerian Pariwisata dan Ekonomi Kreatif pada tahun 2013, namun hanya bertahan 3 tahun. Sebaliknya Ketua Panitia alam periode 2016-2017 tidak berpengalaman (aktor yang lain berpengalaman), hasilnya festival Legu Gam menjadi kegiatan pariwisata yang bertaraf lokal; (3) Adanya pengetahuan khusus aktor dalam kegiatan ritual adat (pihak Kesultanan Ternate).

Motivasi bersama akan tercipta jika legitimasi internal dimiliki secara merata pada semua aktor yang terlibat dalam proses kolaborasi. Legitimasi internal pada ketua panitia periode 20062015 menjadi magnit point untuk menciptakan motovasi bersama bagi aktor-aktor yang lain namun sebaliknya aktor-aktor yang menempati struktur (tidak termasuk ketua panitia) legitimasi internal terbentuk dengan baik tetapi tidak pada ketua panitia atau dengan kata lain legitimasi internal rendah sehingga festival Legu Gam levelnya menurun menjadi kegiatan pariwisata bertaraf lokal.

\section{Kapasitas Melakukan Aksi Bersama}

Tujuan dari kolaborasi adalah untuk menghasilkan sesuatu yang diinginkan secara bersama-sama yang tidak dapat dicapai secara mandiri. Hilman (1994) menggambarkan dalam kolaborasi ada aktivitas yang dilakukan secara kooperatif untuk meningkatkan kapasitas diri dan orang lain untuk mencapai tujuan bersama. Dengan meningkatnya kapasitas individu setelah adanya kolaborasi akan menjadi dasar pemberdayaan kelompok, yang sering didiskusikan sebagai prinsip demokrasi yang mendasari kolaborasi (Leach, 2006).

Kapasitas dalam melakukan aksi bersama berhubungan dengan kemampuan organisasi atau individu yang terlibat dalam tindakan collaborative governance pada festival Legu Gam dalam mencapai hasil yang 
efektif, efesien dan berkelanjutan. Kapasitas untuk melakukan aksi bersama ditekakan pada kolaborasi yang terjalin dapat mengelola prinsip-prinsip kelembagaan, kepemimpinan dan sumber daya.

\section{Desain Kelembagaan Kolaborasi}

Kelembagaan kolaborasi selalu melekat dengan norma yang melandasi pembentukan lembaga kolaborasi dan tindakan yang nantinya dilakukan tak bisa dipisahkan dari organisasi atau individu yang ada dalam sebuah kolaborasi. Dalam pelaksanaan festival Legu Gam kelembagaan kolaborasi sudah dibentuk melaluk Idin Kolano atau surat keputusan Sultan Ternate yang mengesahkan panitia pelaksana festival Legu Gam yang di terbitkan pada Bulan Oktober tahun sebelumnya pada pelakasaan kegiatan. Struktur kepanitiaan mencerminkan keterwakilan dari stakeholders yang terlibat dalam proses kolaborasi. Keterwakilandalam kepanitian setiap tahun sangat tergantung dari masukan stakeholder yang terlibat namun tidak serta merta dapat mengintervensi keputusan Sultan Ternate yang mengesahkan struktur panitia festival Legu Gam.

Komposisi dalam struktur Kepanitian festival Legu Gam mencerminkan adanya keterwakilan stakeholders yang memiliki kapasitas kultural dan struktural yang menempati posisi sebagai Ketua dan Sekertaris. Ketua Umum Panitia tetap di pegang oleh stakeholder yang mewakili pihak kesultanan Ternate, dan beberapa posisi ketua diisi oleh stakeholder yang mewakili pemerintah Kota Ternate, Pemerintah Propinsi Maluku Utara dan Tokoh Masyarakat. Desain kelembagaan kolaborasi berdasarkan pada Idin Kolano telah terbentuk dengan baik setidaknya menunjukkan bahwa pembentukan dan prosedur kolaborasi berasaskan pada khitah Sultan Ternate meskipun pada pelaksanaannya melibatkan pihak lain.

\section{Kepemimpinan Kolaborasi}

Kepemimpinan merupakan salah satu syarat yang harus dipenuhi dalam melakukan aksi bersama. Kepemimpinan dalam kolaborasi lebih mengarah pada bentuk jaringan bukan berbentuk hierarki. Dengan demikian setiap stakeholders berada pada posisi sama. Menurut Emerson et.al (2012) peran pemimpin dalam proses kolaborasi meliputi: (1) sebagai pihak yang menginisiasi penggalangan dukungan untuk kolaborasi; (2) inisiator forum kolaborasi; (3) sebagai fasilitator atau 
mediator; (4) representasi dari aktor dan kolaborasi; (5) share knwoledge; (6) mendorong pemanfaatan teknologi informasi dalam proses kolaborasi dan (7) advokasi publik.

Untuk festival Legu Gam struktur kepemimpinan lebih berbentuk hierarki dimana masing-masing posisi merupakan representasi dari stakeholders yang terlibat. Peran yang dimainkan oleh pemimpin dalam festival Legu Gam sangat vital mengingat kegiatan dalam Legu Gam dibagi kedalam dua bentuk kegiatan, bila kegiatan yang bersifat adat dan budaya Ternate maka kegiatan tersebut menjadi kewenangan pihak kesultanan dan Paniti hanya bertindak sebagai fasilitator dan mediator sedangkan kegiatan yang berupa kegiatan pariwisata menjadi kewenangan panitia. Dalam promosi festival Legu Gam ketua panitia menginisiasi penggalangan dukungan dengan mengundang pihak pemerintah daerah dan kalangan swasta untuk bekerjasama.

\section{SIMPULAN}

Dalam dinamika pelaksanaan festival Legu Gam tidak lagi merupakan representasi seni dan budaya Ternate tetapi mulai meluas menjadi kontestasi seni dan budaya Moloku Kie Raha yang dipadu-padankan dengan budaya, kontemporer. Namun tetap mengacu pada falsafah adat seatorang (adat dan aturan) untuk memaknai keragaman budaya dan etnik untuk pembangunan Maluku Utara.

Dinamika collaborative governance dalam pelaksanaan festival Legu Gam yang dilakukan oleh Pihak Kesultanan Ternate, Pemerintah Kota Ternate dan pemerintah Propinsi Maluku Utara serta pihak Swasta yang ditandai dengan pembentukan forum kolaborasi yakni panitia festival Legu Gam. Dasar yang dijadikan sebagai legitimasi dalam pembentukan forum kolaborasi adalah Idin Kolano atau surat keputusan Sultan Ternate. Adanya forum kolaborasi menunjukkan bahwa keterwakilan dalam proses kolaborasi tidak sebatas simbolis melainkan penegasan secara subtansi keterwakilan pada proses kolaborasi. Dimana forum kolaborasi berperan sebagai instrumen untuk merumuskan bentuk, jenis kegiatan dan strategi pencapaian serta pengambilan keputusan.

Dalam forum kolaborasi, pengambilan keputusan dilakukan secara kolaboratif, keputusan diputuskan dalam rapat panitia. Akan tetapi keputusan 
yang terkait dengan ritual wajib adat dalam Legu Gam pemangku adat kesultanan yang memiliki kewenangan dalam pelaksanaan sedangkan Panitia Festival Legu Gam hanya sebagai fasilitator atau even organizer dalam pelaksanan ritual wajib adat tersebut.

$$
\text { Kelembagaan kolaborasi }
$$

dibentuk melalui Idin Kolano, dimana struktur wadah kolaborasi merepresentasikan stakeholders yang terlibat. Pengambilan keputusan dilakukan dalam wadah kolaborasi, namun dalam ritual wajib adat pengambilan keputusan di bawah kendali pihak kesultanan, panitia festival Legu Gam hanya bertindak sebagai fasilitator. Peran pemimpin dalam festival Legu Gam adalah menginisiasi forum kolaborasi guna menggalang dukungan dan sinergi program dengan pemda serta pihak Swasta untuk pendanaan.

\section{DAFTAR PUSTAKA}

Ansell, Chris and Alisaon Gass. 2007. "Colaborative Governance in Theory and Practice", Journal of Public Adminitration Research and Theory.

Bryson, John M., Barbara C. Crosby, and Melissa Middleton Stone. 2006. The design and implementation of cross-sector collaborations: Propositions form the literature. Public Administration Review 66:44-55.

D. Ngar-yin dan P. Hills. 2010. "Collaborative Governance for sustainable Development: Wind Resource Asessment in Xinjian and Guandong Province", China.

Dorcas A. Ayeni dan O. J Ebohon. 2013. Exploring Sustainable Tourism In Nigeria For Development Growth. European Scientific Journal September Edition, Vol 8, No 2

Dwiyanto, Agus. 2010. Manajemen Pelayanan Publik: Peduli, Inklusif dan Kolaboratif. Gadjah Mada University Press. Yogyakarta.

Emerson , K. Natabachi, T and Balogh, $\mathrm{S}$, 2011. "An Integrative Framework for Collaborative Governance", Journal of Public Administration Research and Theory.

Greewnald. 2008. "Organization: Management Without Control". Thousand Oaks. CA: Sage Publication.

Hardy, Chintia, and Nelson dan Philip. 1998. "Strategic of Engagment: Lesson from the critical Examination of Collaboration and Conflict in an 
Sumitro S. Syawal dan Suleman Samuda - Dinamika Collaborative Governanace...

Interorganizational Domain”.

Organization Science 9(2).

Imperial, Mark. T. 2005. Using Collaboration as a Governance Strategi: Lesson form Six Watershed Management Programs. Administration and Society. Vol. 37 (3). Hal. 281317

Kaha. K, Yohanes. 2015. Collaborative Governance Dalam Pembangunan Pariwisata Berkelanjutan di Taman Nasional Komodo Manggarai Barat NTT. Tesis.Pascasarjana Manajemen dan Kebijakan Publik. Universitas Gadjah Mada. Tidak dipublikasikan

Kumorotomo, Wahyudi. Dkk 2013. Transformasi Layanan Jakarta Comuter Line: Studi tentang Collaborative Governance di sektor publik. Jurusan Manajemen dan Kebijakan Publik, Fisipol UGM.

Lee, S. Jin. dan Yoo, D. Sang. 2012. The Adoption of Collaborative Governance Institutions: The EPA-States Performance Partnership Agreements (PPAS). International Review of Public Administration. Vol. 17 (2). Hal 143-161

Lemos, M.R. dan Agrawal, A. 2006. Environmental Governance.
Annual Review Environment Resources. Vol 31. Hal. 297-325.

Lynn, Lawrence E., Carolyn J Heinrich and Carolyn J. Hill. 2001:7. “ Improving Governance: A new logic for empirical research". Washingtonn DC: Georgetown Univ Press

Miles and Huberman. 1994. "Qualitative Data Analysis; Second Edition". Sage Publications, Inc.

Nasrulhaq. 2014. Collaborative Governance dalam Program Makassar Green and Clean (MGC) 2008-2013. Tesis. Program Pascasarjana Manajemen dan Kebijakan Publik. Fisipol. UGM. Tidak dipublikasi.

O’Leary, Rosemary, Lisa Blomgren Bingham, and Catherine Gerard.2006 ."Special issue on collaborative public managemen". Public Administration Review 66:1-170

Ostrom, Elinor. 1990. Governing the commons: The evolution of institutions for collective action. Cambridge: Cambridge Univ. Press.

Pendit, Nyoman S. 1999. "Ilmu Pariwisata Sebuah Pengantar Perdana". Jakarta : Pradnya Paramita 
NATAPRAJA Vol. 5 No. 2, Desember 2017

Soekadijo. 2000. "Anatomi Pariwista".

Jakarta : Gramedia. 